\title{
The spatial distribution of hydrogen ions at topside ionosphere in local daytime
}

\author{
Xuhui Shen ${ }^{1}$ and Xuemin Zhang ${ }^{2, *}$ \\ ${ }^{I}$ Institute of Crustal Dynamics, China Earthquake Administration, Beijing, China \\ ${ }^{2}$ Institute of Earthquake Forecasting, China Earthquake Administration, Beijing, China
}

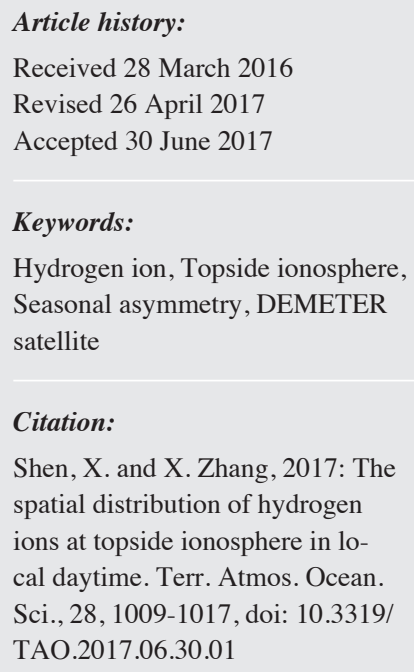

Keywords:

Hydrogen ion, Topside ionosphere, Seasonal asymmetry, DEMETER satellite

Citation:

Shen, X. and X. Zhang, 2017: The spatial distribution of hydrogen ions at topside ionosphere in local daytime. Terr. Atmos. Ocean. Sci., 28, 1009-1017, doi: 10.3319/ TAO.2017.06.30.01

\begin{abstract}
Using DEMETER and DMSP satellite data, the spatial distribution of hydrogen ion $\left(\mathrm{H}^{+}\right)$in local daytime has been compared and analyzed. At $840 \mathrm{~km}$ of DMSP height, the seasonal variations of $\mathrm{H}^{+}$density is basically symmetric, with similar density values near to the magnetic equator at northern hemisphere in December and at southern hemisphere in June. But at DEMETER satellite height, the peak $\mathrm{H}^{+}$density shows obvious enhancement at northern hemisphere in December solstice, while with approximate small values at both hemispheres in June. This spatial distribution feature is totally different with other ions such as $\mathrm{O}^{+}$and $\mathrm{He}^{+}$at the topside ionosphere. And also it influences the transition height in topside ionosphere, with lower transition height over northern hemisphere in December season at $10-20^{\circ} \mathrm{N}$ than those at equator and over southern hemisphere in June season. The solstitial asymmetry index (AI) of $\mathrm{H}^{+}$at $670 \mathrm{~km}$ altitude gives the significant December season enhancement over northern hemisphere, which is typically reversed with electron density $(\mathrm{Ne})$ and ion density (Ni) with large numbers over southern hemisphere in December season. Finally combining with the distribution of $\mathrm{H}$ atoms and neutral wind velocity in upper atmosphere, the forming mechanism and asymmetry feature of peak $\mathrm{H}^{+}$ density is discussed. It is illustrated that the upwelling movement at equatorial area and northward neutral wind play important roles in $\mathrm{H}^{+}$peak drift in December season at DEMETER satellite altitude below the transition height where $\mathrm{H}^{+}$is not the main composition in the local daytime in solar minimum years.
\end{abstract}

\section{INTRODUCTION}

Three species of ions distribute in the topside ionosphere, including oxygen, hydrogen, and helium ions $\left(\mathrm{O}^{+}\right.$, $\mathrm{H}^{+}, \mathrm{He}^{+}$). They are the major three particles with positive charge, and maintain equivalent charges with electrons. At topside ionosphere, $\mathrm{H}^{+}$becomes gradually the main component beyond the upper transition height (height at which total light ions fraction is 50\%), and it plays an important role in understanding the coupling process between atmosphere and ionosphere. Many scientists have studied the temporal variations of ion composition in ionosphere by using satellite observations. Borgohain and Bhuyan (2010) studied the solar cycle variation of ion densities from SROSS C2 and FORMOSAT-1 over Indian low and equatorial latitudes, in which $\mathrm{O}^{+}$dominates the altitude of $500-600 \mathrm{~km}$ and $\mathrm{H}^{+}$

\footnotetext{
* Corresponding author

E-mail:zhangxm96@126.com
}

concentration shows negative correlation with F10.7 solar flux. Gladyshev et al. (2012) exhibited the ion composition from DEMETER, and they obtained the dependence of ion concentration with solar and geomagnetic activity. Kutiev et al. (1980) investigated the $\mathrm{O}^{+}-\mathrm{H}^{+}$transition level by using OGO-6 satellite at $400-1100 \mathrm{~km}$ altitude to illustrate the pronounced dip latitude dependence of transition level. Coley et al. (2010) presented the variations of ion temperature and density at low latitudes by CINDI from the C/NOFS spacecraft, and they found that during solar minimum, the $\mathrm{O}^{+}$ to $\mathrm{H}^{+}$transition height is very low and at the highest altitudes (about $850 \mathrm{~km}$ ) measured $\mathrm{H}^{+}$comprises over $75 \%$ of the ionosphere at all local times. However the difference in spatial distribution of ion compositions has been less studied.

DEMETER satellite was launched on 29 June 2004 and ended operation in December 2010. It was designed as a sun-synchronous orbit, with all descending orbits crossing 
the equator at specific time of LT (local time) 10:30 and ascending ones at LT 22:30 (Cussac et al. 2006). The scientific payload of IAP (Instrument d'Analyse du Plasma) composed of two independent instruments. The first one is a retarding potential analyzer (APR) that performs the energy analysis of the rammed ions and retrieves the density and temperature of the major ions $\mathrm{O}^{+}, \mathrm{He}^{+}, \mathrm{H}^{+}$, as well as the component of their velocity along the line of sight of the analyzer. The second one is an ion drift analyzer (ADV) that allows to essentially determine the direction of the bulk velocity of the major heavy ions, $\mathrm{O}^{+}$(Berthelier et al. 2006). In the previous studies (Zhang et al. 2015), the solar cycle variations in ion composition and ion temperature have been analyzed, in which almost reversed features in $\mathrm{O}^{+}$and light ions $\left(\mathrm{H}^{+}\right.$and $\mathrm{He}^{+}$) were revealed with solar cycles during $2005-2010$. Here the spatial distribution of $\mathrm{H}^{+}$in local daytime is presented, and its formation processes is discussed.

\section{DATA ANALYSIS IN NI $\left(\mathrm{H}^{+}\right)$}

In order to reflect the long term variations in plasma parameters, the time series are rebuilt by daily observation for certain local time. Here the down-orbits data from north to south are averaged by all longitude at different geomagnetic latitudes at stable local time 10:30 in a day from DEMETER satellite, to represent their global temporal variation features during 2005 - 2010, and the longitude differences are discussed in the spatial distribution section.

\subsection{The Spatial Distribution of DEMETER Satellite}

As shown in Fig. 1, the time series of three main species $\left(\left[\mathrm{O}^{+}\right],\left[\mathrm{H}^{+}\right],\left[\mathrm{He}^{+}\right]\right)$at topside ionosphere are presented with latitudes, and also the ion temperature recorded by IAP onboard DEMETER is exhibited simultaneously. From the PI of IAP on DEMETER (Berthelier et al. 2006), it can be known that the accuracy of ions is 2 to $\sim 10 \%$ depending on $\mathrm{Ni}$. An interesting phenomenon is revealed in hydrogen ions $\left(\mathrm{H}^{+}\right)$, that is the peak $\mathrm{H}^{+}$is concentrated at geomagnetic latitude of $10^{\circ} \mathrm{N}$ in December season of northern hemisphere but it does not occur at conjugate southern hemisphere during the June season (the second panel in Fig. 1) in each year. This feature is quite different from those in $\mathrm{O}^{+}$and $\mathrm{He}^{+}$ (Fig. 1), because these two parameters both present nearly symmetric distribution, being alternatively enhanced at their individual summer seasons over two hemispheres in each year although with different amplitude. On the contrary, the maxima of $\mathrm{H}^{+}$are clearly just located around 0 $-20^{\circ} \mathrm{N}$ geomagnetic latitude in local daytime in winter season of northern hemisphere, but peak $\mathrm{H}^{+}$disappear in June season at southern hemisphere, which illustrate obvious seasonal asymmetry feature in $\mathrm{H}^{+}$at the altitude of $670 \mathrm{~km}$ of DEMETER satellite. Compared with $\left[\mathrm{O}^{+}\right]$, the peak season of $\left[\mathrm{H}^{+}\right]$is in December over northern hemisphere, but at this season peak $\left[\mathrm{O}^{+}\right]$is distributed at southern hemisphere. As for $\left[\mathrm{He}^{+}\right]$, the interhemispheric asymmetry is quite obvious, with maximum $\left[\mathrm{He}^{+}\right]$in northern hemisphere for December much greater than those in southern hemisphere for June. Its northern peaks at December season are quite similar with $\left[\mathrm{H}^{+}\right]$, but other weak peaks are still detected in June season at southern hemisphere, which almost disappears in $\left[\mathrm{H}^{+}\right]$in southern winter season. It should be noted here that these seasonal comparisons have both a sampling bias due to the longitudinal averaging and a bias due to significant changes in the solar flux for different periods. From the bottom panel about ion temperature (Ti), its valley season at both hemispheres is just reversed to peak of $\left[\mathrm{H}^{+}\right]$. Especially at solar minimum years of 2008 - 2009, lower Ti occurs in large areas in December season over northern hemisphere, where the areas with big number of $\left[\mathrm{H}^{+}\right]$and $\left[\mathrm{He}^{+}\right]$are enlarged also, therefore certain negative correlation is included in the relationship of $\left[\mathrm{H}^{+}\right]$and $\left[\mathrm{He}^{+}\right]$with Ti.

To verify this feature in $\mathrm{H}^{+}$, Fig. 2 displays the global distribution of $\mathrm{H}^{+}$in June and December in 2008 with grid of $1^{\circ} \times 1^{\circ}$ in geographic latitude and longitude from DEMETER satellite in local daytime. It can be seen that the peak values are mostly lower than $2500 \mathrm{~cm}^{-3}$ in June solstice around the geomagnetic equator, while they exceed $8000 \mathrm{~cm}^{-3}$ in December solstice (Fig. 2b). The different spatial distribution of peak regions is also revealed in two seasons. In June solstice, the $\mathrm{H}^{+}$almost distributes symmetrically between $\pm 15^{\circ}$ latitudes at both sides of the geomagnetic equator over most longitudes (Fig. 2a). But in December season, the peak $\mathrm{H}^{+}$is obviously exhibited around $15^{\circ} \mathrm{N}$ geographic latitude over eastern hemisphere and in $\pm 15^{\circ}$ around the magnetic equator over western hemisphere. Therefore, in June solstice $\mathrm{H}^{+}$is symmetry relative to the geomagnetic equator, but in December solstice northern $\mathrm{H}^{+}$is enhanced significantly. More than $2 / 3$ regions in $\mathrm{H}^{+}$peak are located at northern hemisphere in December solstice, which coincides with the peak $\mathrm{H}^{+}$around $10^{\circ} \mathrm{N}$ geomagnetic latitude over northern hemisphere as shown in Fig. 1. Compared with the results from Gladyshev et al. (2012) about $\mathrm{H}^{+}$variations during 2004 2008 , it also demonstrated big-amplitude peaks from September to February of next year with same annual phase at latitude of $-15^{\circ} \mathrm{S}$ to $25^{\circ} \mathrm{N}$, which gives the same characteristic in $\mathrm{H}^{+}$concentration with ours.

\subsection{The Spatial Distribution of $\mathbf{H}^{+}$from DMSP Satellite}

To validate this spatial feature in $\mathrm{H}^{+}$, data onboard DMSP F15 satellite is also collected. Because this satellite data is only published to the end of 2005 , here we choose the June and December in 2005 to do the comparison with DEMETER. The altitude of this satellite is $840 \mathrm{~km}$, and the local time is around 9:30, with one hour difference with DEMETER. In order to ensure the reliability of the data quality, the lost data with record of -999999 , and the 

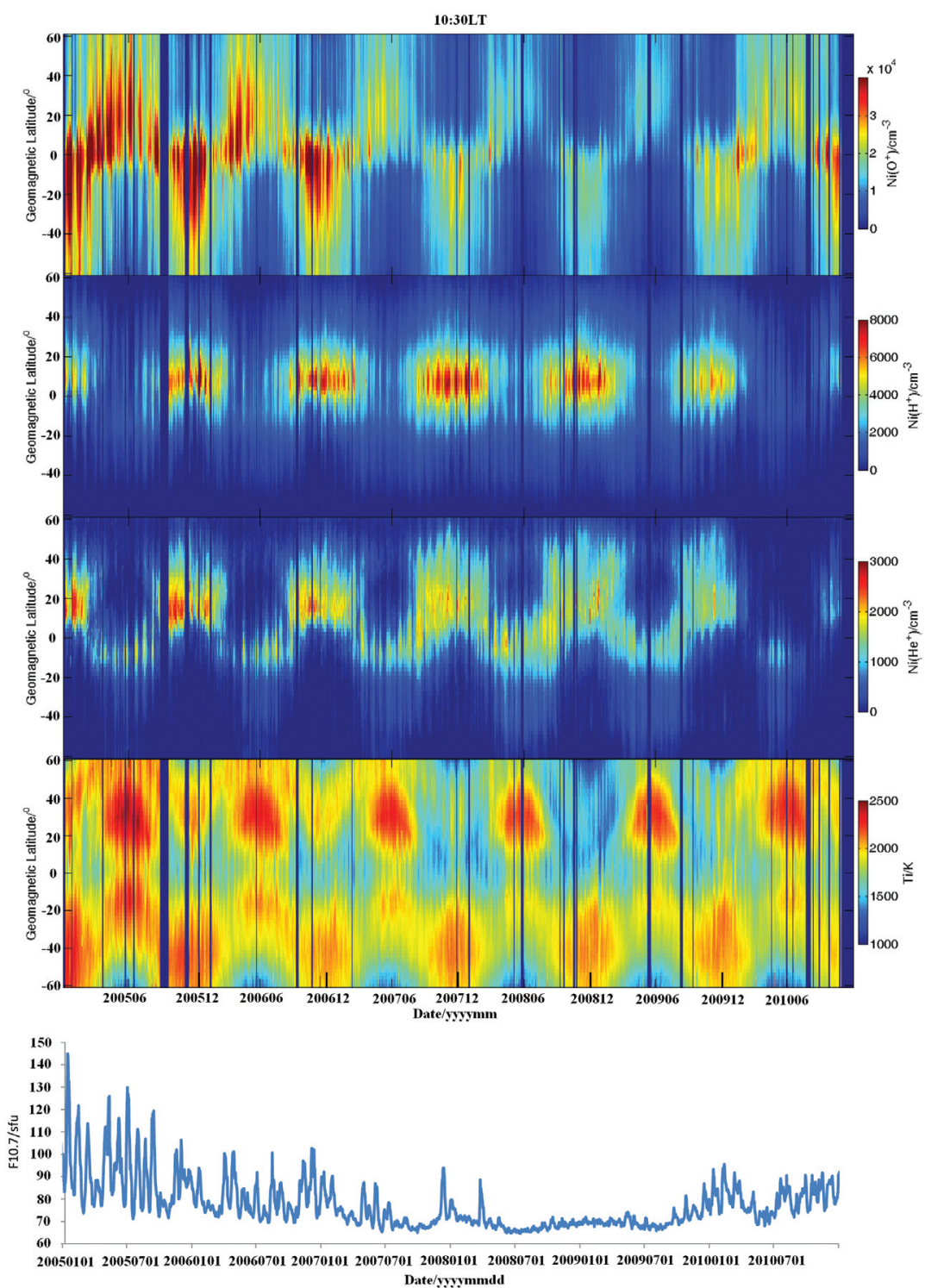

Fig. 1. The temporal and spatial distribution of ion composition and ion temperature (from top to the bottom: $\mathrm{O}^{+}, \mathrm{H}^{+}, \mathrm{He}^{+}, \mathrm{Ti}$ ) during $2005-2010$ in local daytime from DEMETER satellite. (Color online only)
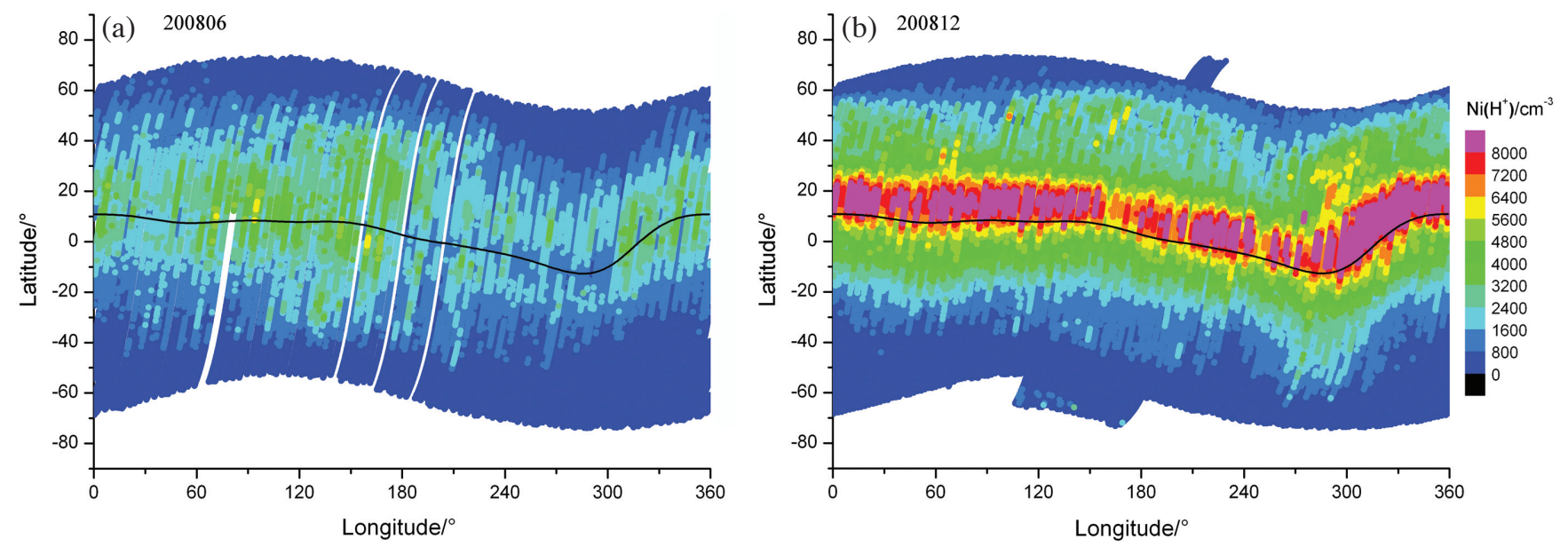

Fig. 2. The spatial distribution of $\mathrm{H}^{+}$in June (a) and December (b) of 2008 at LT1030. (Color online only) 
negative percentage records for any species are all removed. And according to the data quality flag, only the data with good quality (marked with 1 in the data) are selected out. Figure 3 shows that in June the $\mathrm{H}^{+}$peak is just at its south side of the magnetic equator (Fig. 3a). In December solstice (Fig. 3b), the spatial shape is similar with that in June solstice, but the main peak $\mathrm{H}^{+}$concentrating over northern hemisphere of the magnetic equator. Although the maximal values are not located at the same longitudes in two seasons, the general feature of $\mathrm{H}^{+}$peak at the DMSP altitude is much more symmetrical relative to that at DEMETER altitude. West et al. (1997) had studied the composition at topside ionosphere by using DMSP satellite data under high and low solar activities. Their results showed that $\mathrm{H}^{+}$became the main composition at $840 \mathrm{~km}$ altitude in lower solar activity levels, and $\mathrm{H}^{+}$latitude distribution remained quite symmetric at all local times. These features are all consistent with ours.

Compared the two satellite data, it is found that peak $\mathrm{H}^{+}$ density increases quickly, being more than 2 times of that in 2008, which may be related to the higher altitude of DMSP with more concentration of $\mathrm{H}^{+}$, and with high solar activity in 2005 than in 2008. The similar spatial distribution of two satellites is that peak $\mathrm{H}^{+}$is at the winter hemisphere relative to the magnetic equator in December. From DMSP satellite, the amplitudes of $\mathrm{H}^{+}$concentration are near to each other in June and December solstice at two hemispheres, which is quite different with quick decrease at southern part in June solstice on DEMETER. Therefore, in June solstice, the two satellites present different feature in the same season, while in December both satellites are similar in spatial distribution of $\mathrm{H}^{+}$. From the terrestrial ionosphere model at $50-4000 \mathrm{~km}$ from Kohnlein (1989), $\mathrm{O}^{+}$is being replaced by $\mathrm{H}^{+}$as the main ionic constituent at approximately $800 \mathrm{~km}$, which is depended on latitude and local time etc. The spatial distribution of $\mathrm{H}^{+}$also presents significant difference at different altitudes where $\mathrm{H}^{+}$is or not the dominant composition as shown in this paper.

\subsection{The Upper Transition Height in Topside Ionosphere}

González et al. (1992) have used observations from both the Bennett ion mass spectrometer and the retarding potential analyzer on board the Atmosphere Explorer E satellite to study the longitudinally averaged $\mathrm{O}^{+}, \mathrm{H}^{+}$, and $\mathrm{He}^{+}$ concentrations from $150-1100 \mathrm{~km}$ in the equatorial ionosphere during the 1975 - 1976 solar minimum. Their results presented that the peak $\mathrm{H}^{+}$concentrations were about $2.5 \times$ $10^{4} \mathrm{~cm}^{-3}$ during the day and $10^{4} \mathrm{~cm}^{-3}$ at night and vary little with season. And the $\mathrm{O}^{+} / \mathrm{H}^{+}$transition altitude lay between 750 and $825 \mathrm{~km}$ during the day and between 550 and $600 \mathrm{~km}$ at night. Aponte et al. (2013) studied the incoherent scatter radar measurements made at Arecibo Observatory $\left(18.35^{\circ} \mathrm{N}\right.$, $66.75^{\circ} \mathrm{W}$ ), at a geomagnetic latitude of $30^{\circ} \mathrm{N}$ (or $46.7^{\circ}$ dip latitude), during the recent extreme solar minimum of 2007 - 2009, and they obtained that during the geomagnetically quiet period of October 2009, the transition height $h_{t}$, where $\left[\mathrm{O}^{+}\right]=\left[\mathrm{H}^{+}\right]+\left[\mathrm{He}^{+}\right]$, was observed at altitudes as low as 800 - $820 \mathrm{~km}$ during daytime and descended as low as $450 \mathrm{~km}$ during the night. Klimenko et al. (2015) gave the $\mathrm{O}^{+} / \mathrm{H}^{+}$transition height obtained in GSM TIP model for UT12:00 on 15 January 2009 , in which the seasonal asymmetry feature of the transition height is evident with less altitude in the winter hemisphere than in the summer one. And in the morning longitudinal sector it drops below $500 \mathrm{~km}$ at mid-latitudes of the northern hemisphere, but reaching the maxima of $700 \mathrm{~km}$ near the equator and about $1000 \mathrm{~km}$ at middle latitudes in the afternoon sector. Heelis et al. (2009) used the observing data from C/NOFS satellite in 2008, and they found that the transition height resided near $450 \mathrm{~km}$ at night and rose to only $850 \mathrm{~km}$ during the daytime. So according to their results, the daytime $\mathrm{O}^{+} / \mathrm{H}^{+}$transition altitude was higher than the 660 - $710 \mathrm{~km}$ of DEMETER, and the daytime $\mathrm{O}^{+}$would be the
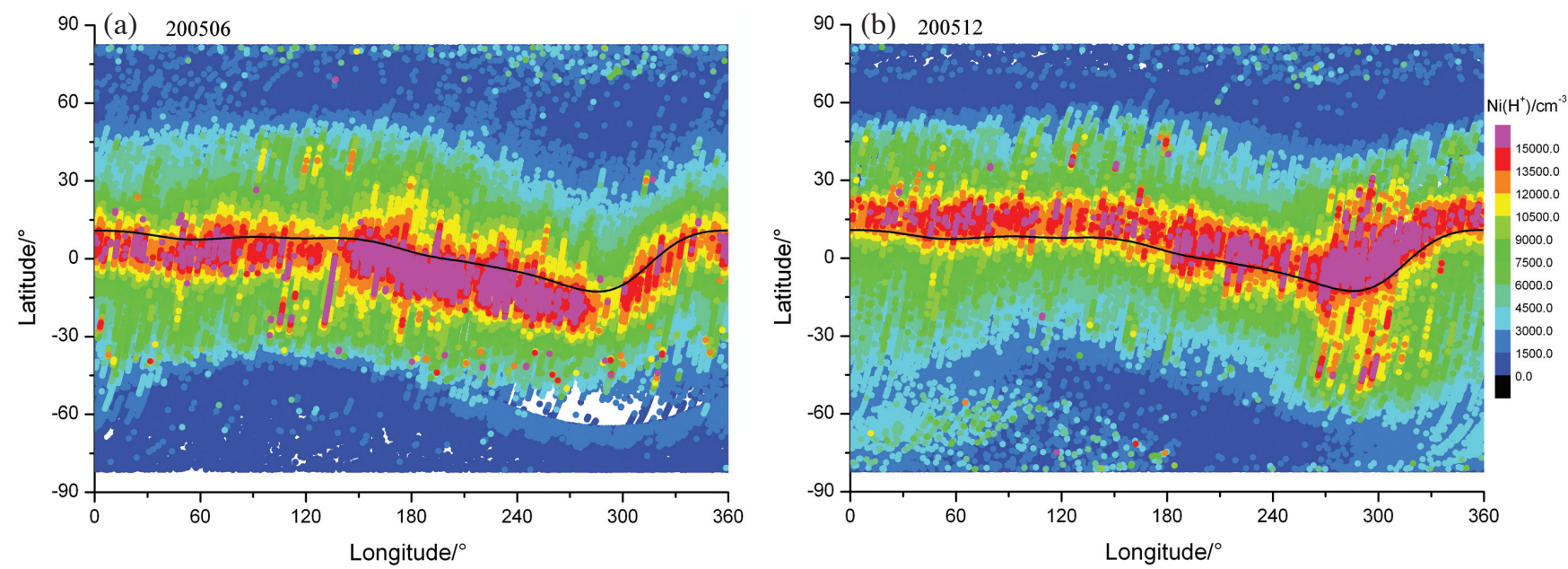

Fig. 3. The spatial distribution of $\mathrm{H}^{+}$in June (a) and December (b) of 2005 in local daytime from DMSP F15. (Color online only) 
main constitution among three ion species. But in nighttime, the transition height was much lower than that of DEMETER, $\mathrm{H}^{+}$concentration would become quite large among the three ion species. In order to verify this phenomenon, Fig. 4 exhibited the temporal curves of the percentage of $\mathrm{O}^{+}$and $\left[\mathrm{H}^{+}\right.$ $+\mathrm{He}^{+}$] during 2005 - 2010 at low latitudes in local daytime at low latitudes over Southern hemisphere (Fig. 4a) and northern hemisphere (Fig. 4b) respectively. It can be seen that over southern hemisphere (Fig. 4a), $\left[\mathrm{O}^{+}\right]$percentage decreased with the solar flux since 2005, reaching its minimum in 2008, when $\left[\mathrm{H}^{+}+\mathrm{He}^{+}\right]$percentage increased, so in solar minimum 2008 - 2009, $\left[\mathrm{O}^{+}\right]$percentage was less than $50 \%$, which means the transition height was lower than $660 \mathrm{~km}$ near the equator in 2008 and 2009 in local daytime around 10:30. As shown in Fig. 4b, northern $\left[\mathrm{O}^{+}\right]$percentage exhibits peak light ions in December season, showing reversed annual phase with the southern one at same latitude. And the latitudes with large light ion percentage more than $50 \%$ continues to $25^{\circ} \mathrm{N}$, not like the southern one only being to $5-15^{\circ} \mathrm{S}$. Based on the observation of IAP from DEMETER, during the $23^{\text {rd }} / 24^{\text {th }}$ solar minimum, the transition height reduced quickly, even lower than $660 \mathrm{~km}$ in daytime around LT 10:30. Yue et al. (2010) studied the ionospheric transition height derived from COSMIC satellite, and they found that the transition height was very low, with significant local time, latitude and seasonal variations, during the extremely low solar minimum of 2008. From their results, during June-August around LT 10:00 and 22:00, the transition heights were all lower than $600 \mathrm{~km}$ within the latitude of $\pm 10^{\circ}$, which well coincided with the results in daytime in this paper.

\section{DISCUSSION AND CONCLUSION}

With the quick decrease of solar activity to the
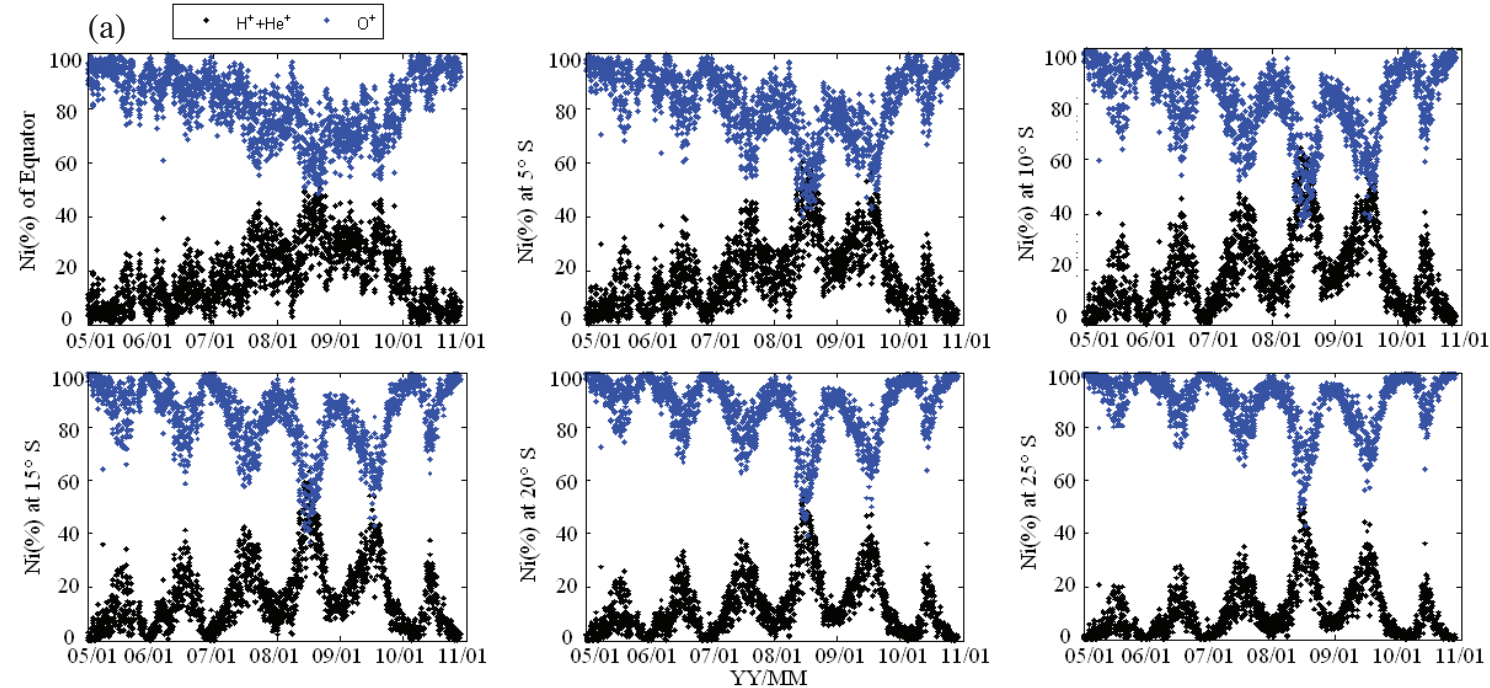

(b)
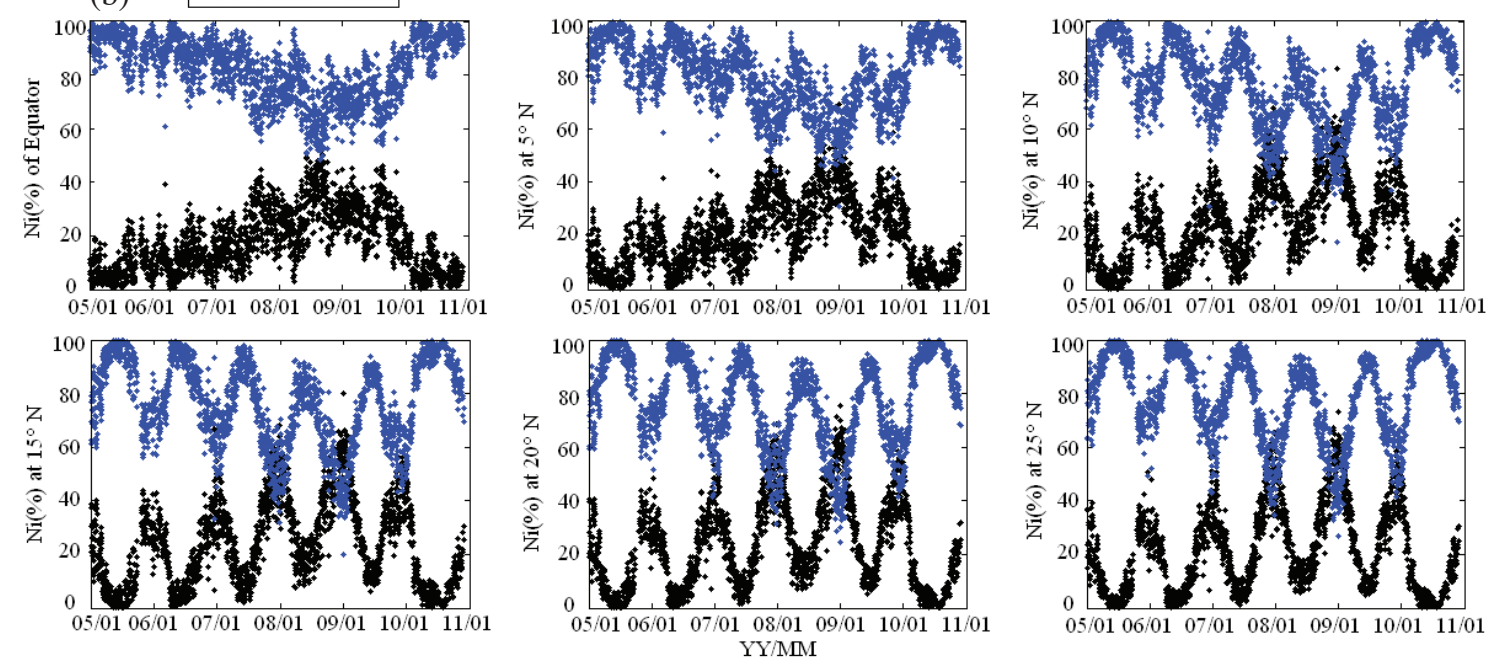

Fig. 4. The solar cycle variation in the percentage of $\left[\mathrm{O}^{+}\right]$and $\left[\mathrm{H}^{+}+\mathrm{He}^{+}\right]$at $0-25^{\circ}$ latitudes in $5^{\circ}$ interval during $2005-2010$ in local daytime from DEMETER. (a) Southern hemisphere; (b) northern hemisphere; blue points represent the percentage of $\mathrm{O}^{+}$ions and black points are the percentage of light ions of $\mathrm{H}^{+}$and $\mathrm{He}^{+}$. (Color online only) 
extremely low solar year of $2008, \mathrm{H}^{+}$increases as shown by its maximum at the winter hemisphere, while the total $\mathrm{Ni}$ and the main species of $\mathrm{O}^{+}$decline continuously from 2005 - 2008, presenting opposite variation trends with solar activity at DEMETER satellite altitude of $670 \mathrm{~km}$. In the three major species of topside ionosphere, only $\mathrm{H}^{+}$shows special totally asymmetrical seasonal variations, with its peak values display a local maximum in the winter hemisphere, while the total $\mathrm{Ni}$ and $\mathrm{O}^{+}$all exhibit local peaks in the summer hemisphere. Compared with $\mathrm{H}^{+}$spatial distribution from DEMETER at $670 \mathrm{~km}$ and DMSP at $840 \mathrm{~km}$, it is found that the solstitial asymmetry in $\mathrm{H}^{+}$becomes much significant at lower altitudes closer to the $\mathrm{O}^{+} / \mathrm{H}^{+}$transition height in local daytime.

Charge exchange is one of the principal chemical source, and sink for $\mathrm{H}^{+}$in the topside ionosphere as $\mathrm{O}^{+}+\mathrm{H} \leftrightarrow \mathrm{H}^{+}$ $+\mathrm{O}$. During the day, $\mathrm{O}^{+}$ions created by solar photoionization exchange electric charge to $\mathrm{H}^{+}$through the reaction $\mathrm{O}^{+}$ $+\mathrm{H} \leftrightarrow \mathrm{H}^{+}+$O. From Fig. 1, $\mathrm{O}^{+}$peaks occur in the summer season with similar density over both hemispheres around the magnetic equator. To understand the $\mathrm{H}^{+}$production, the $\mathrm{H}$ atom distribution has been calculated by NRLMSISE-00 model at $400 \mathrm{~km}$ height as shown in Fig. 5 in solstice of 2008 with the same local daytime as DEMETER at 10:30. It can be seen that, $\mathrm{H}$ also has seasonal variation, with larger density in winter hemisphere than summer hemisphere. From this distribution, $\mathrm{H}^{+}$density should also be larger in June over southern hemisphere due to the peak density of $\mathrm{O}^{+}$ at this region in the same season. But at DEMETER altitude, the $\mathrm{H}^{+}$peaks are almost symmetric in June solstice at two sides of the magnetic equator, with no typical peaks occurring at the winter or summer hemisphere, therefore it cannot explain the low density and symmetrical spatial distribution of $\mathrm{H}^{+}$in June season. While in December season, major $\mathrm{H}$ atoms are located beyond $20^{\circ} \mathrm{N}$ over northern hemisphere, which may be connected with the north shift of peak $\mathrm{H}^{+}$in this season a little. So from the distribution of $\mathrm{H}$ atoms, it may affect the $\mathrm{H}^{+}$density at topside ionosphere with higher values at winter hemisphere, but it is not the main factor to cause the seasonal asymmetry in $\mathrm{H}^{+}$density.

A prevailing summer to winter wind across the magnetic equator is significantly responsible for the altitude dependence of $\mathrm{O}^{+} / \mathrm{H}^{+}$transition height Modulation in the $\mathrm{O}^{+} /$ $\mathrm{H}^{+}$transition height and associated transport of plasma at the topside ionosphere. Rishbeth et al. (2000) had calculated the global distribution of neutral wind in December, March, and June respectively, and their results showed that at latitude of $\pm 50^{\circ}$, the neutral wind presented different features. In June the neutral particles moves to north at northern hemisphere and to south direction over southern hemispheres, while in December, the neutral wind mainly pointed to east-west and northward direction at middle and low latitudes over both hemispheres. Bhuyan et al. (2002) gave the diurnal variations of neutral wind velocity for December and June solstice at three geomagnetic latitudes from the equation of Chauhan and Gurm (1980), in which the neutral wind velocity direction were opposite to each other at $10^{\circ} \mathrm{N}$ and $10^{\circ} \mathrm{S}$ in June, but they showed similar direction in December, both pointing to the north at LT10:00. West and Heelis (1996) analyzed the longitudinal modulations of ion compositions at topside ionosphere by meridional and zonal neutral winds, and they demonstrated that the summer to winter meridional winds in solstice season mainly regulate the $\mathrm{F}$ peak height, with the zonal winds enhancing or opposing the effects of the meridional winds at the longitude $150-270^{\circ} \mathrm{E}$ and 300 $360^{\circ} \mathrm{E}$ with significant magnetic declination there. So these papers all revealed the seasonal differences in horizontal neutral wind at middle and low latitudes, and their effects on the longitudinal and latitudinal modulations of ion compositions. The supplement of $\mathrm{H}^{+}$from southern hemisphere in December may fill up the loss of $\mathrm{H}^{+}$at northern hemisphere and enhance the $\mathrm{H}^{+}$concentration at low latitude, combined
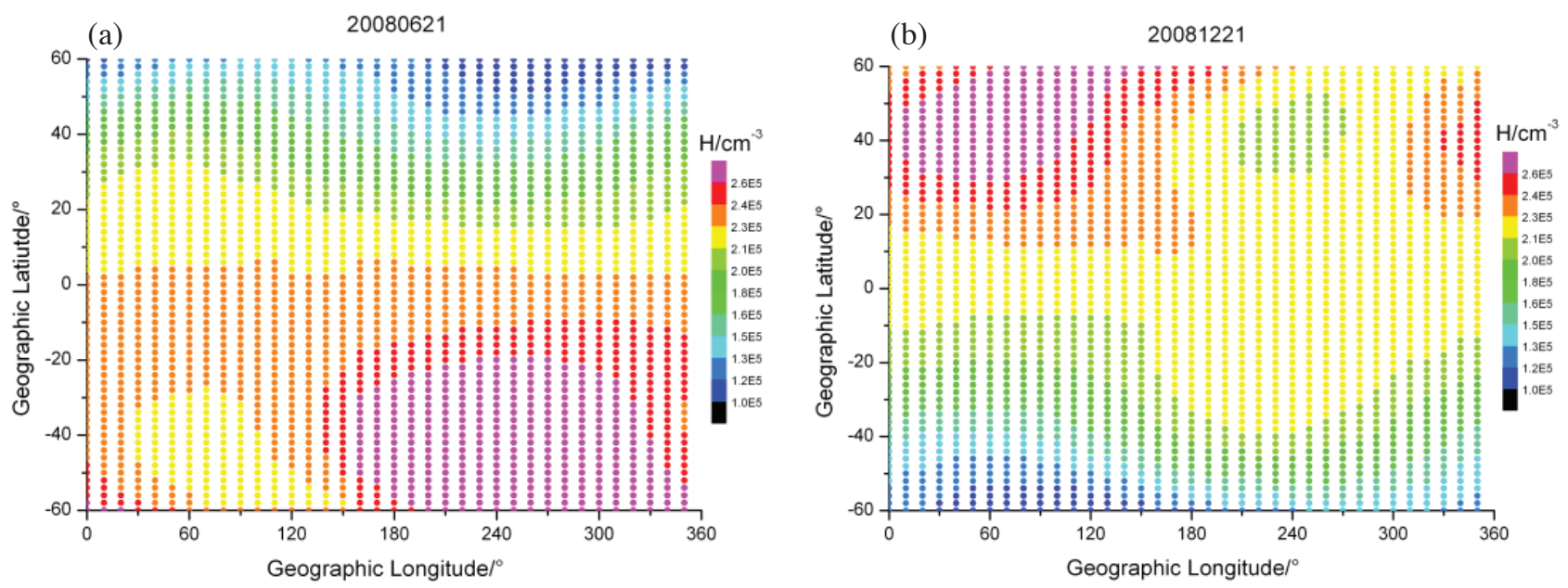

Fig. 5. Spatial distribution of $\mathrm{H}$ atoms at the altitude of $400 \mathrm{~km}$ on 21 June 2008 (a) and 21 December 2008 (b). (Color online only) 
action of the neutral wind and upward electromagnetic plasma drift at equator.

Summarized the spatial distribution of $\mathrm{H}^{+}$from DEMETER and DMSP, the seasonal asymmetry is obvious, with maxima $\mathrm{H}^{+}$around the equator in June and moving to north in December. The disappearance of peak $\mathrm{H}^{+}$ in June over southern hemisphere is the biggest difference with two other ion species. Some scientists have studied the asymmetry features in $\mathrm{Ne}$ and $\mathrm{Ni}$ by using satellite observations (Mendillo et al. 2005; Liu et al. 2007; Zhang et al. 2014, 2015), and all solstitial AI (Asymmetry Index, $\left.A I=\left[\left(N i_{i}^{N}+N i_{i}^{S}\right)_{D e c}-\left(N i_{i}^{N}+N i_{i}^{S}\right)_{J u n}\right] /\left[\left(N i_{i}^{N}+N i_{i}^{S}\right)_{D e c}+\left(N i_{i}^{N}+N i_{i}^{S}\right)_{J u n}\right]\right)$ values in these papers are larger than 0 in local daytime, which illustrates that plasma density in December season is always larger than that in June solstice, that is generally known as the "Annual Anomaly". In this paper, the peak values in $\mathrm{H}^{+}$are hard to be found over southern hemisphere whenever in June or December season at the topside ionosphere from DEMETER and DMSP satellites, so the solstitial asymmetry is much clearer (Fig. 6). From Fig. 6a, the longitude averaged $\mathrm{H}^{+}$concentration is quite bigger in December season than that in June season, in which the June $\mathrm{H}^{+}$is a little larger only at $30-60^{\circ}$ geomagnetic latitude over southern hemisphere. By using the AI equation from Mendillo et al. (2005), the solstitial asymmetry is calculated as shown in Fig. 6b. And large AIs occur at $0-20^{\circ}$, reaching about 0.45 . More $\mathrm{H}^{+}$ions are located at northern hemisphere in December solstice, not at southern hemisphere as $\mathrm{Ne}$ and total $\mathrm{Ni} . \mathrm{He}^{+}$is similar with $\mathrm{H}^{+}$in December solstice, but it is not as significant as $\mathrm{H}^{+}$with vanished June peaks over southern hemisphere.

According to the results of Liu et al. (2007), the differences in $[\mathrm{O}]$ at the two solstices are larger in the southern hemisphere than in the northern hemisphere at $500 \mathrm{~km}$ altitude from NRLMSISE-00, and the increase in [O] will increase the production rate of ions, which in turn increase the ion and electron densities. As shown in Fig. 5, the $[\mathrm{H}]$ also shows similar seasonal spatial distribution as [O]. As for the $\mathrm{H}^{+}$ions, they do not distribute at the region with more [O] and $[\mathrm{H}]$ in December solstice over southern hemisphere, but move to north, concentrating at the latitude around $10^{\circ} \mathrm{N}$. So the distribution of neutral compositions obtained using NRLMSISE model does not look as the key factor for forming the special spatial distribution of $\mathrm{H}^{+}$ions.

Besides the ion production rate, at the $\mathrm{H}^{+}$peak region with low temperature of $T_{i}$ at December season, it may illustrate the low loss rate of light ions at low ion temperature season and regions. In addition, another key factor to influence the spatial distribution of ions is the plasma transport due to neutral wind, electromagnetic drift and diffusion. In local daytime around 9:30 - 10:30, under the heating action from the Sun and tidal movement from the atmosphere, the electrons and ions at the lower ionosphere move upwards and across the horizontal geomagnetic power lines around the equator to interact with the geomagnetic field, resulting in the equatorial ionospheric anomaly (EIA). At the altitude of DEMETER and DMSP, double peaks at $\pm 20^{\circ}$ converge to one single peak (Zhang 2014) around the equator. After the upward movement, the zonal wind will play a role to determine the spatial distribution of ions. Considering the different movement features in December and June season in neutral wind, it may contribute to the forming of $10^{\circ}$ latitude $\mathrm{H}^{+}$peaks in northern hemisphere. As for the longitudinal difference of peak $\mathrm{H}^{+}$, it should be mainly controlled by $E \times$ $B$ and meridional wind in low latitudinal area. The high latitude $\mathrm{H}^{+}$are clearly driven by the seasonal changes in composition and photoproduction, while closer to the magnetic equator the interhemispheric transport and $E \times B$ drifts play important roles in its seasonal variations.

In this paper, the spatial distribution of $\mathrm{H}^{+}$at DEMETER altitude in local daytime has been analyzed, and the significant asymmetric feature is revealed in two solstitial seasons. Some main features are concluded as following. (1) At DEMETER altitude of $670 \mathrm{~km}, \mathrm{H}^{+}$peaks occur at the (a)

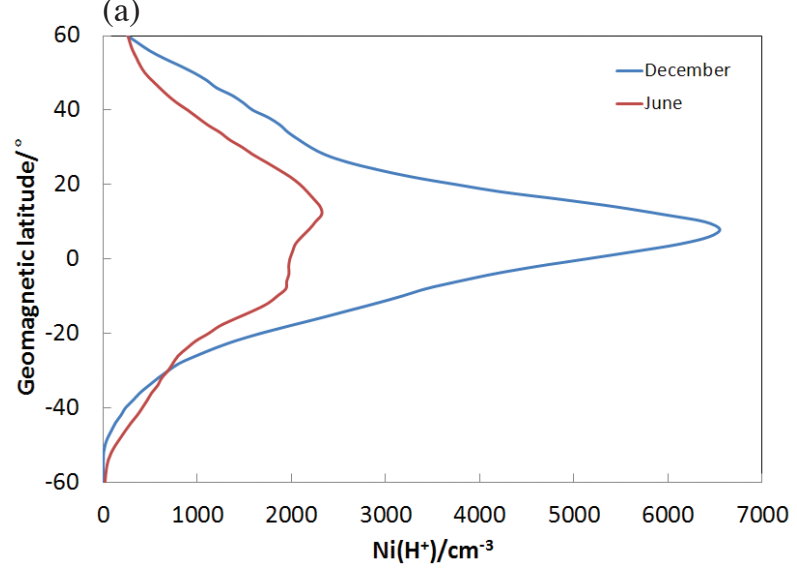

(b)

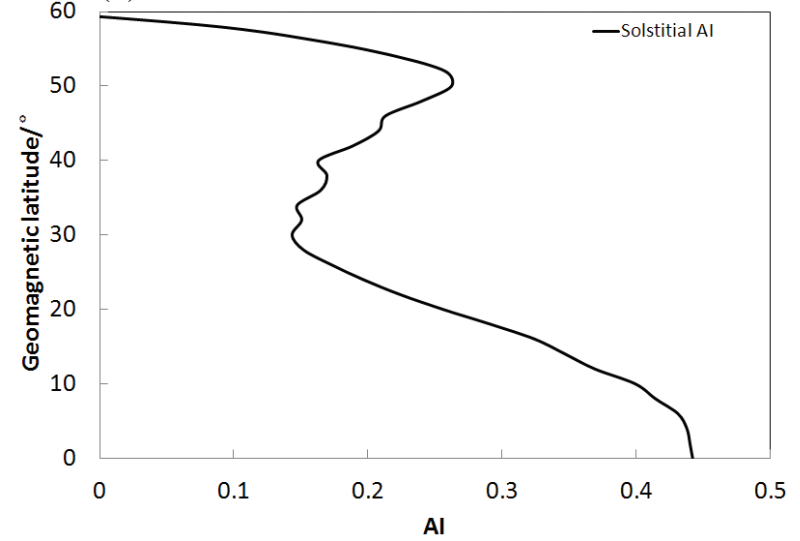

Fig. 6. The solstitial asymmetry in $\mathrm{H}^{+}$concentration in 2008. (a) Comparison in two seasons; (b) solstitial asymmetry AI. (Color online only) 
winter hemisphere in local daytime during solar minimum years when observations are made at or below the transition height, being opposite with $\mathrm{O}^{+}$peaks and $\mathrm{Ne}$ always located at summer hemisphere.

(2) The significant seasonal asymmetry has been found in $\mathrm{H}^{+}$peaks, with big values in December solstice at northern hemisphere, but small values in June at southern hemisphere at solar minimum years when observations are made above the transition height. Compared with the $\mathrm{H}^{+}$distribution at DMSP, it gives a seasonal symmetric feature at higher levels of solar activity and altitudes below the transition height. This illustrates the different behavior of the constituent species dependent on the location of the transition height. The same characteristic of two satellites is that peak $\mathrm{H}^{+}$occurs near the magnetic equator at winter hemisphere in solstitial seasons.

(3) The $\mathrm{H}^{+}$spatial distribution varies severely. Significant latitude asymmetries at a constant altitude exists in the $\mathrm{H}^{+}$when it is the minor species, but these asymmetries are reduced when $\mathrm{H}^{+}$is the major ion.

(4) During solar minimum, $\mathrm{H}^{+}$density increases in a larger latitudinal scale, and then makes the $\mathrm{H}^{+} / \mathrm{O}^{+}$transition height decreasing quickly there.

(5) By considering multi factors, when observations are made on flux tubes for which the transition height lies well below the satellite, the $\mathrm{H}^{+}$concentration is largely controlled by the transport of $\mathrm{H}^{+}$and remains relatively symmetric about the magnetic equator. For observations on flux tubes where the transition height is close to or above the satellite, a significant asymmetry about the magnetic equator is produced by the interhemispheric transport and charge exchange of $\mathrm{O}^{+}$.

Acknowledgements This paper is jointly supported by National International Scientific and Technology Cooperation Project (2014DFR21280, 4141101064) and the major project of Institute of Earthquake Forecasting, CEA (2015IES0101). The authors thank DEMETER and DMSP center for providing the plasma data.

\section{REFERENCES}

Aponte, N., C. G. M. Brum, M. P. Sulzer, and S. A. Gonzalez, 2013: Measurements of the $\mathrm{O}^{+}$to $\mathrm{H}^{+}$transition height and ion temperatures in the lower topside ionosphere over Arecibo for equinox conditions during the 2008-2009 extreme solar minimum. J. Geophys. Res., 118, 4465-4470, doi: 10.1002/jgra.50416. [Link]

Berthelier, J. J., M. Godefroy, F. Leblanc, E. Seran, D. Peschard, P. Gilbert, and J. Artru, 2006: IAP, the thermal plasma analyzer on DEMETER. Planet. Space Sci., 54, 487-501, doi: 10.1016/j.pss.2005.10.018. [Link]

Bhuyan, P. K., P. K. Kakoty, and S. B. Singh, 2002: Theoretical simulation of $\mathrm{O}^{+}$and $\mathrm{H}^{+}$densities in the Indian low latitude F-region and comparison with observations. Ann. Geophys., 20, 1956-1966, doi: 10.5194/ angeo-20-1959-2002. [Link]

Borgohain, A. and P. K. Bhuyan, 2010: Solar cycle variation of ion densities measured by SROSS C2 and FORMOSAT-1 over Indian low and equatorial latitudes. J. Geophys. Res., 115, A04309, doi: 10.1029/2009JA014424. [Link]

Chauhan, N. S. and H. S. Gurm, 1980: Ambipolar diffusion and vertical drift at low latitudes. Ind. J. Rad. Space Phys., 9, 265-273.

Coley, W. R., R. A. Heelis, M. R. Hairston, G. D. Earle, M. D. Perdue, R. A. Power, L. L. Harmon, B. J. Holt, and C. R. Lippincott, 2010: Ion temperature and density relationships measured by CINDI from the C/NOFS spacecraft during solar minimum. J. Geophys. Res., 115, A02313, doi: 10.1029/2009ja014665. [Link]

Cussac, T., M. A. Clair, P. Ultre-Guerard, F. Buisson, G. Lassalle-Balier, M. Ledu, C. Elisabelar, X. Passot, and N. Rey, 2006: The Demeter microsatellite and ground segment. Planet. Space Sci., 54, 413-427, doi: 10.1016/j.pss.2005.10.013. [Link]

Gladyshev, V. A., A. Y. Shchekotov, N. V. Yagova, J. J. Berthelier, M. Parrot, O. S. Akentceva, L. N. Batanskii, E. N. Fedorov, T. M. Mulyarchik, and O. A. Molchanov, 2012: Concentration of ions in the topside ionosphere as measured obboard the DEMETER satellite: Morphology and dependence on solar and geomagnetic activity. Cosmic Res., 50, 103-115, doi: 10.1134/S0010952512020037. [Link]

González, S. A., B. G. Fejer, R. A. Heelis, and W. B. Hanson, 1992: Ion composition of the topside equatorial ionosphere during solar minimum. J. Geophys. Res., 97, 4299-4303, doi: 10.1029/91JA03111. [Link]

Heelis, R. A., W. R. Coley, A. G. Burrell, M. R. Hairston, G. D. Earle, M. D. Perdue, R. A. Power, L. L. Harmon, B. J. Holt, and C. R. Lippincott, 2009: Behavior of the $\mathrm{O}+/ \mathrm{H}+$ transition height during the extreme solar minimum of 2008. Geophys. Res. Lett., 36, L00C03, doi: 10.1029/2009GL038652. [Link]

Klimenko, M. V., V. V. Klimenko, I. E. Zakharenkova, and I. V. Cherniak, 2015: The global morphology of the plasmaspheric electron content during Northern winter 2009 based on GPS/COSMIC observation and GSM TIP model results. Adv. Space Res., 55, 2077-2085, doi: 10.1016/j.asr.2014.06.027. [Link]

Kohnlein, W., 1989: A model of the terrestrial ionosphere in the altitude interval $50-4000 \mathrm{~km} \mathrm{I}$. Atomic ions $\left(\mathrm{H}^{+}\right.$, $\left.\mathrm{He}^{+}, \mathrm{N}^{+}, \mathrm{O}^{+}\right)$. Earth Moon Planets, 45, 53-100, doi: 10.1007/BF00054660. [Link]

Kutiev, I., R. A. Heelis, and S. Sanatani, 1980: The behavior of the $\mathrm{O}^{+}-\mathrm{H}^{+}$transition level at solar maximum. J. Geophys. Res., 85, 2366-2372, doi: 10.1029/JA085iA05p02366. [Link] 
Liu, L., B. Zhao, W. Wan, S. Venkartraman, M. L. Zhang, and X. Y. Yue, 2007: Yearly variations of global plasma densities in the topside ionosphere at middle and low latitudes. J. Geophys. Res., 112, A07303, doi: 10.1029/2007JA012283. [Link]

Mendillo, M., C. L. Huang, X. Pi, H. Rishbeth, and R. Meier, 2005: The global ionospheric asymmetry in total electron content. J. Atmos. Sol. Terr. Phys., 67, 1377-1387, doi: 10.1016/j.jastp.2005.06.021. [Link]

Rishbeth, H., I. C. D. Muller-Wodarg, L. Zou, T. J. FullerRowell, G. H. Millward, R. J. Moffett, D. W. Idenden, and A. D. Aylward, 2000: Annual and semiannual variations in the ionospheric F2-layer: II. Physical discussion. Ann. Geophys., 18, 945-956, doi: 10.1007/ s00585-000-0945-6. [Link]

West, K. H. and R. A. Heelis, 1996: Longitude variations in ion composition in the morning and evening topside equatorial ionosphere near solar minimum. J. Geophy. Res., 101, 7951-7960, doi: 10.1029/95ja03377. [Link]

West, K. H., R. A. Heelis, and F. J. Rich, 1997: Solar activity variations in the composition of the low lati- tude ionosphere. J. Geophys. Res., 102, 295-305, doi: 10.1029/96JA03031. [Link]

Yue, X., W. S. Schreiner, J. Lei, C. Rocken, Y. H. Kuo, and W. Wan, 2010: Climatology of ionospheric upper transition height derived from COSMIC satellites during the solar minimum of 2008. J. Atmos. Solar-Terr. Phys.,72,1270-1274, doi: 10.1016/j.jastp.2010.08.018. [Link]

Zhang, X., 2014: Electron density comparison between IRI 2007 and DEMETER satellite data in solar minimum year. Terr. Atmos. Ocean. Sci., 25, 559-571, doi: 10.3319/TAO.2014.02.24.01(AA). [Link]

Zhang, X., X. Shen, J. Liu, L. Yao, G. Yuan, and J. Huang, 2014: The asymmetrical features in electron density during extreme solar minimum. Adv. Space Res., 54, 2236-2248, doi: 10.1016/j.asr.2014.08.028. [Link]

Zhang, X., X. Shen, and G. Yuan, 2015: The solar cycle varaitions of plasma parameters and their correlations at topside ionosphere from DEMETER during 20052010. Adv. Space Res., 56, 1374-1388, doi: 10.1016/j. asr.2015.06.038. [Link] 